\title{
Measuring Co-movements Between US and European Stock Markets*
}

\author{
Alessandra Bonfiglioli and Carlo A. Favero \\ IEP,Università L.Bocconi and IEP, Università L.Bocconi and CEPR \\ June 6,2000
}

\begin{abstract}
In this paper we concentrate on the consequences for the European stock market of a correction of the US Stock market. We explicitly consider the distinction between interdependence and contagion. We provide separate answers to the following questions:

(i) is there long-term interdependence between US and Europe, i.e. does the equilibrium for European shares depend on the equilibrium for US shares?

(ii) Is there short-term interdependence and contagion between US and European stock markets, i.e do short term fluctuations of the US share prices spill over to European share prices and is such co-movement stable in occasion of the occurrence of high volatility episodes?

JEL Classification: F30, F40, G15

Keywords: Contagion, Stock Market, Interdependence, Structural models

${ }^{*}$ This paper was first presented at Bocconi University, INSEAD, CIDE and University of Naples.We thank seminar participants for comments. We also thank our discussants Fabio-Cesare Bagliano and Diego Lubian for their comments. Roberto Botter contributed comments, discussion and assistance with the empirical work. Address for correspondance Carlo A. Favero, IGIER-Università Bocconi, Via Salasco 5, 20136 Milan, Italy e-mail: carlo.favero@uni-bocconi.it, Alessandra Bonfiglioli, IEP-Università Bocconi, Via Gobbi 5, 20136 Milan Italy, e-mail: alessandra.bonfiglioli@uni-bocconi.it
\end{abstract}




\section{Introduction}

On the 5th December 1996, when the Dow Jones index was floating around 7000, with the yield on 10-year US bonds at 5.8 per cent, the Fed Chairman, Alan Greenspan, warned the market against "irrational exuberance". Since then the DJ has gone past the level of 11000, to track back towards 10500 at the beginning of year 2000, while the yield on long bonds has gone back to the December 1996 level, after having reached a minimum at 3.8 in September 1998. In the mean time, while the Fed Chairman has better qualified his views on irrational exuberance (see http: \\www.bog.frb.fed.us), the question of the potential consequences of a correction of the US stock market of, say $25 \%$, has been taken up by a number of academics (see Bernanke and Gertler, 1999). In this paper we concentrate on the potential spill-over effect of such a correction on the European stock markets. This issue has important consequences for monetary policy and portfolio allocation.

Bernanke and Gertler(1999), using a traditional "broad credit channel" argument, point out that the extent to which an asset price contraction weakens private sector balance sheets, and therefore affects consumption and investment, depends on the degree and sectoral distribution of risk exposure. After many years of expansion and strong profits in the corporate and banking sectors, US balance sheets are in excellent conditions and a correction in the stock markets, paired with an appropriate responses by the FED, is likely to have only transitory contractionary effects. In contrast, a similar 25 per cent correction in Europe, where economies are struggling out of a period of persistently slow growth and high unemployment, is likely to have much more persistent effects on the macroeconomic conditions, even if the ECB were to respond to such a shock by easing liquidity.

The relevant question for portfolio allocation is related but different. How would a correction in the US stock markets affect conditional correlations among asset prices? A first possible scenario is that the response of European markets to the US correction is in line with the historical pattern of interdependence between the two markets. In this case the conditional correlations among the asset prices would be substantially unaltered. We would still observe the macroeconomic effects described above but portfolio allocation and risk evaluations based on some estimates of conditional variance-covariance matrix of the relevant returns based on historical data would still be valid. In this case no unpredictable effect of the US correction on financial sectors' balance sheets would arise. However, an alternative sce- 
nario is possible, in which the correction in the US stock market generates a structural break in the pattern of interdependence of asset prices. Such an event would heavily affect portfolio allocation and risk evaluations based on historical estimates of the variance-covariance matrix of the relevant returns, and render the impact of a correction on balance sheets more dramatic and unpredictable.

The empirical literature on the transmission of financial shocks (Rigobon, 1999) has recently introduced an important distinction between the two concepts of contagion and interdependence. Interdependence is measured by identifying cross-market linkages, while contagion is measured by modifications of such linkages during crisis periods. A strong co-movement of European and US stock markets in presence of a correction of the US stock market is compatible both with interdependence and contagion. However, we would have interdependence when such comovement is in line with the historically measured simultaneous feedback between the two markets, while contagion is identified by excess co-movements.

Contagion among stock markets has been traditionally measured by using correlations and by defining it as a significant increase in correlations across markets. This traditional approach has been recently criticized by Rigobon and Forbes (1998). Changing correlations cannot be directly related to contagion in presence of interdependence. In a structural model featuring constant interdependence across countries, cross market correlations are bound to increase in a period of turmoil, when stock market volatility increases. Rigobon and Forbes consider the 1997 East Asian crisis, the 1994 Mexican Peso crisis and the 1987 US stock market crash to show that unadjusted correlation coefficients support the contagion hypothesis, while tests based on coefficients adjusted for interdependence find virtually no-contagion. Further evidence is proposed by Rigobon (2000) through the implementation of an IV procedure for a direct test of the null of no contagion only interdependece. This strand of research crucially hinges on structural modelling of interdependence, with the adoption of a limited information approach.

We base our analysis of interdependence and contagion on full information estimation of a structural model. Following the LSE econometric approach (see Hendry, 1995), we construct our structural model starting from a general reduced form.

Our reduced form is a Vector Error Correction model, based on the theory espoused by Graham and Dodd (1951) and already exploited by Lander et al.(1997) for the US case, which assumes that stock returns tend to restore an 
equilibrium relationship between forecast earnings yield on common stocks and yield on bonds. We specify our general reduced form model on six variables: US and European share prices, earnings, and redemption yields on 10-year benchmark bonds. We consider a sample of monthly data 1980-1999 and use diagnostic tests, in particular tests for residuals normality to validate our reduced form. Such strategy leads us to the inclusion of a number of point dummies into the model. Interestingly, some of them capture the episodes of high volatility in stock markets. On this validated reduced form, we perform cointegration analysis to pin down long-run equilibria. Finally, we proceed to specify a structural model of interdependence and evaluate contagion. The validity of the structural model is tested by verifying the validity of the over-identifying restrictions imposed by our structure on the baseline reduced form. Our specification strategy allows us to provide separate answers to the following questions:

- Is there long-term interdependence between US and Europe, i.e. does the equilibrium for European shares depend on the equilibrium for US shares?

- Is there short-term interdependence and contagion between US and European stock markets, i.e. do short term fluctuations of the US share prices spill over to European share prices and is such co-movement stable in occasion of the occurrence of high volatility episodes?

\section{Interdependence and contagion between US and European stock markets:a general-to- specific approach}

We take the consensus definition of contagion as a change in the international propagation of shocks caused by some country specific factor. In the recent empirical literature on the international propagation of shocks such factor is usually interpreted as a crisis, identifed by a local shock of different magnitude (usually paired with a change in the volatility of shocks). In our specific case we shall consider a situation in which the stock market of one country, the US, has wandered away from its long-run equilibrium values and we shall look at the international effects of a correction. 
Our baseline specification is a reduced form VAR specification for the logarithms of US and European Share prices, $L P_{E U, t}, L P_{U S, t}$ and the vectors of variables candidate to determine their equilibrium: $\mathbf{X}_{E U, t}, \mathbf{X}_{U S, t}$. For the sake of exposition, we consider a first order process, although our empirical model features higher order dynamics.

$$
\begin{aligned}
\left(\begin{array}{c}
L P_{E U, t} \\
L P_{U S, t} \\
\mathbf{X}_{E U, t} \\
\mathbf{X}_{U S, t}
\end{array}\right) & =\left(\begin{array}{llll}
\pi_{11} & \pi_{12} & \boldsymbol{\pi}_{13}^{\prime} & \boldsymbol{\pi}_{14}^{\prime} \\
\pi_{21} & \pi_{22} & \boldsymbol{\pi}_{23}^{\prime} & \boldsymbol{\pi}_{24}^{\prime} \\
\pi_{31} & \pi_{32} & \boldsymbol{\pi}_{33} & \boldsymbol{\pi}_{34} \\
\pi_{41} & \pi_{42} & \boldsymbol{\pi}_{43} & \boldsymbol{\pi}_{44}
\end{array}\right)\left(\begin{array}{c}
L P_{E U, t-1} \\
L P_{U S, t-1} \\
\mathbf{X}_{E U, t-1} \\
\mathbf{X}_{U S, t-1}
\end{array}\right)+\left(\begin{array}{c}
v_{1, t} \\
v_{2, t} \\
\mathbf{v}_{3, t} \\
\mathbf{v}_{4, t}
\end{array}\right) \\
\left(\begin{array}{ll}
v_{1, t} \\
v_{2, t} \\
\mathbf{v}_{3, t} \\
\mathbf{v}_{4, t}
\end{array}\right) & \sim\left[\left(\begin{array}{l}
0 \\
0
\end{array}\right), \Sigma_{t}\right]
\end{aligned}
$$

Note that residuals form our baseline VAR specification are heteroscedastic. This reflects the presence in our data of observations which correspond to periods of turmoil. By using tests of normality and heteroscedasticity of residuals as a guiding criterion, it is then possible to re-specify (1) as : 


$$
\begin{aligned}
& \left(\begin{array}{c}
L P_{E U, t} \\
L P_{U S, t} \\
\mathbf{X}_{E U, t} \\
\mathbf{X}_{U S, t}
\end{array}\right)=\left(\begin{array}{llll}
\pi_{11} & \pi_{12} & \boldsymbol{\pi}_{13}^{\prime} & \boldsymbol{\pi}_{14}^{\prime} \\
\pi_{21} & \pi_{22} & \boldsymbol{\pi}_{23}^{\prime} & \boldsymbol{\pi}_{24}^{\prime} \\
\pi_{31} & \pi_{32} & \boldsymbol{\pi}_{33} & \boldsymbol{\pi}_{34} \\
\pi_{41} & \pi_{42} & \boldsymbol{\pi}_{43} & \boldsymbol{\pi}_{44}
\end{array}\right)\left(\begin{array}{c}
L P_{E U, t-1} \\
L P_{U S, t-1} \\
\mathbf{X}_{E U, t-1} \\
\mathbf{X}_{U S, t-1}
\end{array}\right) \\
& +(I+\Psi D)\left(\begin{array}{l}
u_{1, t} \\
u_{2, t} \\
\mathbf{u}_{3, t} \\
\mathbf{u}_{4, t}
\end{array}\right) \\
& \left(\begin{array}{ll}
u_{1, t} & \\
u_{2, t} & \mid I_{t-1} \\
\mathbf{u}_{3, t} & \\
\mathbf{u}_{4, t}
\end{array}\right) \sim N\left[\left(\begin{array}{l}
0 \\
0
\end{array}\right), \Sigma\right] \\
& \Psi=\left(\begin{array}{cccc}
\psi_{11} & \psi_{12} & \boldsymbol{\psi}_{13}^{\prime} & \boldsymbol{\psi}_{14}^{\prime} \\
\psi_{21} & \psi_{22} & \psi_{23}^{\prime} & \boldsymbol{\psi}_{24}^{\prime} \\
\psi_{31} & \psi_{32} & \boldsymbol{\psi}_{33}^{\prime} & \boldsymbol{\psi}_{34}^{\prime} \\
\psi_{41} & \psi_{42} & \boldsymbol{\psi}_{43}^{\prime} & \boldsymbol{\psi}_{44}^{\prime}
\end{array}\right) \\
& D=\left(\begin{array}{cccc}
d_{1, t} & 0 & 0 & 0 \\
0 & d_{2, t} & 0 & 0 \\
0 & 0 & \mathbf{d}_{3, t} & 0 \\
0 & 0 & 0 & \mathbf{d}_{4, t}
\end{array}\right)
\end{aligned}
$$

where the vectors of dummies $\mathbf{d}_{i, t}$ are identified in order to filter nonnormality out of the original residuals. The coefficients in the matrix $\Psi$ allow the removal of outliers.

On the basis of this specification we proceed to cointegration analysis and reparameterise our system as follows:

$$
\left(\begin{array}{c}
\Delta L P_{E U, t} \\
\Delta L P_{U S, t} \\
\Delta \mathbf{X}_{E U, t} \\
\Delta \mathbf{X}_{U S, t}
\end{array}\right)=\Pi\left(\begin{array}{c}
L P_{E U, t-1} \\
L P_{U S, t-1} \\
\mathbf{X}_{E U, t-1} \\
\mathbf{X}_{U S, t-1}
\end{array}\right)+(I+\Psi D)\left(\begin{array}{l}
u_{1, t} \\
u_{2, t} \\
\mathbf{u}_{3, t} \\
\mathbf{u}_{4, t}
\end{array}\right)
$$

where the matrix $\Pi$ describes the long-run properties of our system. We empirically find, two equilibrium relationships, in this case the rank of $\Pi$ is two and we have $\Pi=\boldsymbol{\alpha} \boldsymbol{\beta}^{\prime}$. By analyzing the adjustment parameters $\boldsymbol{\alpha}$, we are 
able to attribute the equilibria to share prices. By analysing the $\boldsymbol{\beta}$ parameters we are able to address the issue of long-run interdependence, in fact we can test if foreign variables are important in determining domestic share prices in the long-run. In practice the following restrictions on the $\boldsymbol{\alpha}$ and $\boldsymbol{\beta}$ vectors are not rejected for our sample:

$$
\begin{aligned}
\Pi= & \boldsymbol{\alpha} \boldsymbol{\beta}^{\prime} \\
\alpha & =\left(\begin{array}{cc}
\alpha_{11} & \alpha_{12} \\
\alpha_{21} & \alpha_{22} \\
\mathbf{0} & \mathbf{0} \\
\mathbf{0} & \mathbf{0}
\end{array}\right), \beta=\left(\begin{array}{cc}
1 & 0 \\
0 & 1 \\
\boldsymbol{\beta}_{31} & \mathbf{0} \\
\mathbf{0} & \boldsymbol{\beta}_{42}
\end{array}\right)
\end{aligned}
$$

Having completed our analysis of the long-run properties of our system we are left with the following VECM specification for US and European share prices.

$$
\begin{aligned}
\left(\begin{array}{c}
\Delta L P_{E U, t} \\
\Delta L P_{U S, t}
\end{array}\right)= & \left(\begin{array}{ll}
\alpha_{11} & \alpha_{12} \\
\alpha_{21} & \alpha_{22}
\end{array}\right)\left(\begin{array}{c}
L P_{E U, t-1}-L P_{E U, t-1}^{*} \\
L P_{U S, t-1}-L P_{U S, t-1}^{*}
\end{array}\right) \\
& +\Pi_{1}\left(\begin{array}{c}
\Delta \mathbf{X}_{E U, t} \\
\Delta \mathbf{X}_{U S, t}
\end{array}\right) \\
& +\left(I+\left(\begin{array}{ll}
\psi_{11} & \psi_{12} \\
\psi_{21} & \psi_{22}
\end{array}\right)\left(\begin{array}{cc}
0 & 0 \\
0 & d_{2, t}
\end{array}\right)\right)\left(\begin{array}{l}
u_{1, t} \\
u_{2, t}
\end{array}\right)
\end{aligned}
$$

Note that the variables contained in the $\mathbf{X}$ vectors are now, validly, considered as exogenous; moreover the vector of relevant dummies contains only those for the US share prices $\left(d_{1, t}=0\right)$. In fact, this turns out to be the only empirically relevant case for our investigation. The methodology can be extended to more general specifications for the vector of dummies (see, for example, Favero-Giavazzi(2000)).

The simultaneous presence of dummies in both equations is not informative on the relative importance of contagion and interdependence. This issue cannot be resolved by estimating a reduced form and requires the specification of a structural model. The following structural model allows for both contagion and interdependence: 


$$
\begin{aligned}
&\left(\begin{array}{cc}
1 & -\beta_{12} \\
0 & 1
\end{array}\right)\left(\begin{array}{c}
\Delta L P_{E U, t} \\
\Delta L P_{U S, t}
\end{array}\right)=\left(\begin{array}{ll}
\gamma_{11} & \gamma_{12} \\
\gamma_{21} & \gamma_{22}
\end{array}\right)\left(\begin{array}{c}
L P_{E U, t-1}-L P_{E U, t-1}^{*} \\
L P_{U S, t-1}-L P_{U S, t-1}^{*}
\end{array}\right)(\mathfrak{\oplus}) \\
&+\Gamma_{2}\left(\begin{array}{c}
\Delta \mathbf{X}_{E U, t} \\
\Delta \mathbf{X}_{U S, t}
\end{array}\right)+ \\
&\left(I+\left(\begin{array}{ll}
a_{11} & a_{12} \\
a_{21} & a_{22}
\end{array}\right)\left(\begin{array}{cc}
0 & 0 \\
0 & d_{2, t}
\end{array}\right)\right)\left(\begin{array}{c}
\epsilon_{1, t} \\
\epsilon_{2, t}
\end{array}\right) \\
&\left(\begin{array}{ll}
\epsilon_{1, t} & \mid I_{t-1} \\
\epsilon_{2, t}
\end{array}\right) \sim N\left[\left(\begin{array}{l}
0 \\
0
\end{array}\right),\left(\begin{array}{cc}
\sigma_{\epsilon 1}^{2} & 0 \\
0 & \sigma_{\epsilon 2}^{2}
\end{array}\right)\right]
\end{aligned}
$$

In(6), we assumed triangularity in the simultanoeous relationship between US and European Stock prices. Note that such assumption becomes testable when a sufficient number of restriction can be imposed on $\Gamma_{2}$. The presence of contagion is described by $a_{12} \neq 0$, because this indicates that modelling interdependence by explicitly allowing $\beta_{12} \neq 0$, is not enough to describe the way shocks are transmitted across countries in periods of turmoil.

The null of no contagion can then be tested as an over-identifying restriction for our specification. The hypothesis of interdependence only and no contagion is then parametrized as $\mathrm{H}_{0}: a_{12}=0$ which implies the following overidentifying restriction:

$$
\psi_{12}=\beta_{12} a_{22}
$$

Under $\mathrm{H}_{0}$ turmoil in country 2 propagates to country 1 only through interdependence, as described by $\beta_{12}$.

Within this simple framework it is easy to make two related points. First, simple correlations are the wrong indicator to detect contagion. As shown by Rigobon(1999) and by Forbes and Rigobon(1998) a change in the (conditional and unconditional) correlation between $\Delta L P_{E U, t}$ and $\Delta L P_{U S, t}$ does occur during a crisis, quite independently of 'contagion'. Consider, for example, conditional correlations and define:

$$
\rho=\frac{\operatorname{Cov}\left(\Delta L P_{E U, t}, \Delta L P_{U S, t} \mid I_{t-1}\right)}{\sqrt[2]{\operatorname{Var}\left(\Delta L P_{E U, t} \mid I_{t-1}\right) \operatorname{Var}\left(\Delta L P_{U S, t} \mid I_{t-1}\right)}}
$$


the correlation between stock markets. Separate now the sample in "low" and "high" volatility periods, according to the presence of dummies. In the low volatility periods we have

$$
\left(\begin{array}{c}
\Delta L P_{E U, t} \\
\Delta L P_{U S, t}
\end{array}\right)-E\left(\begin{array}{c|c}
\Delta L P_{E U, t} & \mid I_{t-1} \\
\Delta L P_{U S, t} &
\end{array}\right)=\left(\begin{array}{c}
u_{1, t} \\
u_{2, t}
\end{array}\right)
$$

while in the high volatility period:

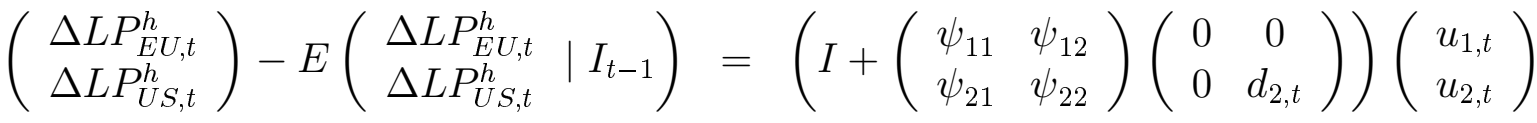

$$
\begin{aligned}
& =\left(\begin{array}{c}
u_{1, t}^{h} \\
u_{2, t}^{h}
\end{array}\right)
\end{aligned}
$$

Next compute $\rho^{l}$, and $\rho^{h}$, the conditional correlations, respectively, in the high and low volatility periods. It can be shown that even under the null of no contagion we have $\rho^{h}>\rho^{l}$. In this case $\left(a_{12}=0\right)$ we have

$$
\begin{gathered}
\rho^{l}=\frac{\beta_{12} \sigma_{\epsilon 2}^{2}}{\sqrt[2]{\left[\beta_{12}^{2} \sigma_{\epsilon 2}^{2}+\sigma_{\epsilon 1}^{2}\right] \sigma_{\epsilon 2}^{2}}} \\
=\frac{1}{\sqrt[2]{1+\frac{\sigma_{1}^{2}}{\beta_{12}^{2} \sigma_{\epsilon 2}^{2}}}} \\
\rho^{h}=\frac{\beta_{12} \sigma_{\epsilon 2}^{2}\left(1+a_{22} d_{2 t}\right)^{2}}{\sqrt[2]{\left[\beta_{12}^{2} \sigma_{\epsilon 2}^{2}\left(1+a_{22} d_{2 t}\right)^{2}+\sigma_{\epsilon 1}^{2}\right] \sigma_{\epsilon 2}^{2}\left(1+a_{22} d_{2 t}\right)^{2}}} \\
=\frac{1}{\sqrt[2]{1+\frac{\sigma_{\epsilon 1}^{2}}{\beta_{12}^{2} \sigma_{\epsilon 2}^{2}\left(1+a_{22} d_{2 t}\right)^{2}}}}
\end{gathered}
$$

and $\rho^{h}>\rho^{l}$.

Second, we can compare our structural framework with the instrumental variables method proposed by Rigobon(2000) to estimate $\beta_{12}$ and control for interdependence in order to detect contagion. The methodology hinges on splitting the sample into high and low volatility periods. An instrument is 
then constructed whose validity is warranted under the null of no contagion, then test of validity of instruments are used as test of contagion. To illustrate this procedure in our context, consider splitting the observations on the dependent variables into high and low volatility periods as follows:

$$
\begin{aligned}
\left(\begin{array}{cc}
1 & -\beta_{12} \\
0 & 1
\end{array}\right)\left(\begin{array}{c}
\Delta L P_{E U, t}^{h} \\
\Delta L P_{U S, t}^{h}
\end{array}\right)= & \left(\begin{array}{ll}
\gamma_{11} & \gamma_{12} \\
\gamma_{21} & \gamma_{22}
\end{array}\right)\left(\begin{array}{c}
L P_{E U, t-1}-L P_{E U, t-1}^{*} \\
L P_{U S, t-1}-L P_{U S, t-1}^{*}
\end{array}\right) \\
& +\Gamma_{2}\left(\begin{array}{c}
\Delta \mathbf{X}_{E U, t} \\
\Delta \mathbf{X}_{U S, t}
\end{array}\right) \\
& +\left(I+\left(\begin{array}{ll}
a_{11} & a_{12} \\
a_{21} & a_{22}
\end{array}\right)\left(\begin{array}{cc}
0 & 0 \\
0 & d_{2, t}
\end{array}\right)\right)\left(\begin{array}{c}
\epsilon_{1, t} \\
\epsilon_{2, t}
\end{array}\right) \\
\left(\begin{array}{cc}
1 & -\beta_{12} \\
0 & 1
\end{array}\right)\left(\begin{array}{c}
\Delta L P_{E U, t}^{l} \\
\Delta L P_{U S, t}^{l}
\end{array}\right)= & \left(\begin{array}{ll}
\gamma_{11} & \gamma_{12} \\
\gamma_{21} & \gamma_{22}
\end{array}\right)\left(\begin{array}{c}
L P_{E U, t-1}-L P_{E U, t-1}^{*} \\
L P_{U S, t-1}-L P_{U S, t-1}^{*}
\end{array}\right) \\
& +\Gamma_{2}\left(\begin{array}{c}
\Delta \mathbf{X}_{E U, t} \\
\Delta \mathbf{X}_{U S, t}
\end{array}\right)+\left(\begin{array}{c}
\epsilon_{1, t} \\
\epsilon_{2, t}
\end{array}\right)
\end{aligned}
$$

We then have :

$$
\Delta \mathbf{L} \mathbf{P}_{E U}=\left(\begin{array}{c}
\Delta \mathbf{L} \mathbf{P}_{E U}^{h} \\
\Delta \mathbf{L} \mathbf{P}_{E U}^{l}
\end{array}\right), \Delta \mathbf{L P}_{U S}=\left(\begin{array}{c}
\Delta \mathbf{L} \mathbf{P}_{U S}^{h} \\
\Delta \mathbf{L} \mathbf{P}_{U S}^{l}
\end{array}\right)
$$

Rigobon considers the problem of estimating $\beta_{12}$ using $\mathbf{w}$ as an instrument for $\Delta \mathbf{L} \mathbf{P}_{U S}$, such that

$$
\mathbf{w}=\left(\begin{array}{c}
\frac{\Delta \mathbf{L} \mathbf{P}_{U S}^{h}}{T^{h}} \\
-\frac{\Delta \mathbf{L P}_{U S}^{l}}{T^{l}}
\end{array}\right),
$$

where $T^{i}$, for $i=h, l$, is the length of the high or low volatility period.

Using $\mathbf{w}$ as an instrument for $\Delta \mathbf{L} \mathbf{P}_{U S}$ leads to the following just-identified IV estimator of the interdependence parameter:

$$
\hat{\beta}_{12}=\left(\mathbf{w}^{\prime} \Delta \mathbf{L} \mathbf{P}_{U S}\right)^{-1} \mathbf{w}^{\prime} \Delta \mathbf{L} \mathbf{P}_{E U}
$$


The two usual conditions for validity and consistency of the IV estimator are checked by looking at the probability limits of $\left(\mathbf{w}^{\prime} \Delta \mathbf{L} \mathbf{P}_{U S}\right)$ and $\left(\mathbf{w}^{\prime} \boldsymbol{\epsilon}_{1}^{*}\right)$, where $\boldsymbol{\epsilon}_{1}^{*}=\boldsymbol{\epsilon}_{1}+a_{12} d_{2 t} \boldsymbol{\epsilon}_{2}$

$$
\begin{aligned}
p \lim \left(\mathbf{w}^{\prime} \Delta \mathbf{L} \mathbf{P}_{U S}\right) & =p \lim \frac{1}{T^{h}} \Delta \mathbf{L} \mathbf{P}_{U S}^{h \prime} \Delta \mathbf{L} \mathbf{P}_{U S}^{h}-p \lim \frac{1}{T^{l}} \Delta \mathbf{L} \mathbf{P}_{U S}^{l \prime} \Delta \mathbf{L} \mathbf{P}_{U S}^{l} \\
& =\left(a_{22} d_{2 t}\right)^{2} \sigma_{\epsilon 2}^{2} \\
p \lim \left(\mathbf{w}^{\prime} \boldsymbol{\epsilon}_{1}^{*}\right) & =\left(a_{12} d_{2 t}\right)^{2} \sigma_{\epsilon 2}^{2}
\end{aligned}
$$

The validity of the instruments is guaranteed under $\mathrm{H}_{0}\left(a_{12}=0\right)$, while their efficiency depends on the degree of heteroscedasticity between the low and high volatility periods (see Rigobon (2000)). The beauty of this approach depends on the fact that it does not require variables other than $\triangle \mathbf{L P}_{U S}$ to implement the IV estimator. Within this framework, contagion can be tested applying a Hausman(1978)-type test for the validity of the instruments. We conclude for the case of the specific problem considerded our proposed procedure is equivalent to the IV approach, for large high volatility sample. The procedure based on the estimation of the structural model with dummies is better geared to deal with cases of short, and possible noncontiguous high volatility episodes, in that the relevant sample size to apply asymptotic theory is that of the whole sample and not of the high volatility sub-sample(s). In the next sections we shall implement our procedure and compare our results with those delivered by the IV approach.

\section{A statistical model for European and US share prices, earnings and long-term inter- est rates}

The baseline of our empirical analysis is a reduced form VAR . We select variables to be included in such model following the lead of traditional analysis (Graham and Dodd Security Analysis, 4th edition, 1962, p.510):

"...Theoretical analysis suggests that both the dividend yield and the earnings yield on common stocks should be strongly affected by changes in the long-term interest rates. It is assumed 
that many investors are constantly making a choice between stock and bond purchases; as the yield on bonds advances, they would be expected to demand a correspondingly higher return on stocks, and conversely as bond yields decline..."

The above statement suggests that either the dividend yield or the earnings yield on common stocks could be used. Together with long-term interest rates to define an equilibrium relationship between the stock and the bond market. This general statement can be justified within the framework of a forward-looking equilibrium models for share-prices.

Define returns on the stock markets as follows:

$$
E_{t}\left(r_{t+1}^{s m}\right)=\frac{D_{t+1}^{e}}{P_{t}}+\frac{P_{t+1}^{e}-P_{t}}{P_{t}}
$$

where $r^{s m}$ are stock market returns, $D$ are dividends and $P$ are share price. By expressing (8) in terms of prices, we have:

$$
P_{t}=\frac{D_{t+1}^{e}}{\left(1+E_{t}\left(r_{t+1}^{s m}\right)\right)}+\frac{P_{t+1}^{e}}{\left(1+E_{t}\left(r_{t+1}^{s m}\right)\right)}
$$

by recursively substituting for future expected price and by imposing the "no-bubbles" transversality condition on (9)we have:

$$
P_{t}=\sum_{i=1}^{n}\left[\frac{D_{t+i}^{e}}{\prod_{i=1}^{n}\left(1+E_{t}\left(r_{t+i}^{s m}\right)\right)^{i}}\right] .
$$
follows:

By defining as $g_{t}$ the rate of growth of dividends we can re-write (10)as

$$
\begin{aligned}
\frac{P_{t}}{D_{t+1}^{e}}= & \frac{1}{1+E_{t}\left(r_{t+1}^{s m}\right)}+\frac{\left(1+E_{t} g_{t+1}\right)}{\left(1+E_{t}\left(r_{t+1}^{s m}\right)\right)\left(1+E_{t}\left(r_{t+2}^{s m}\right)\right)}+ \\
& \ldots+\frac{\left(1+E_{t} g_{t+1}\right) \ldots\left(1+E_{t} g_{t+n}\right)}{\left(1+E_{t}\left(r_{t+1}^{s m}\right)\right)\left(1+E_{t}\left(r_{t+2}^{s m}\right)\right) \ldots\left(1+E_{t}\left(r_{t+n}^{s m}\right)\right)}
\end{aligned}
$$


Define now the risk-premium $r p$ :

$$
r_{t}^{s m}=r_{t}+r p_{t}
$$

where $r$ is the return on the risk-free asset.(10) can then be re-written as

$$
\frac{P_{t}}{D_{t+1}}=f\left(E_{t} r_{t+1, \cdots, E_{t}} r_{t+n}, r p_{t}, E_{t} r p_{t+1}, \ldots, E_{t} r p_{t+n}, g_{t}, E_{t} g_{t+1, \cdots, E_{t}} g_{t+n}\right)
$$

where $\frac{\partial f}{\partial r}<0, \frac{\partial f}{\partial r p}<0 \frac{\partial f}{\partial g}>0$.If the long-term interest rate is positively correlated with future one-period returns(which in turn are equal to the safe one-period return plus a risk premium) and negatively correlated with future earnings growth, then (12) can be linearized to deliver:

$$
\left(\frac{D_{t+1}}{P_{t}}\right)^{*}=a_{0}+a_{1} R_{t}
$$

which justifies the existence of an equilibrium relation between the dividend yields and long-term interest rates. Note that such relation implies cointegration between the long-term interest rates and the dividend yields, if these series are non-stationary, but is not yet enough to establish stock market predictability. In fact the latter is achieved only when stock prices rather then dividends or long-term interest rates adjust in presence of disequilibria.

Having derived an equilibrium for the dividend yield, we can easily extend it to price-earnings:

$$
\left(\frac{E_{t+1}}{P_{t}}\right)^{*}=\left(\frac{D_{t+1}}{P_{t}}\right)^{*}\left(\frac{E_{t+1}}{D_{t+1}}\right)^{*}=\left(a_{0}+a_{1} R_{t}\right)\left(\frac{E_{t+1}}{D_{t+1}}\right)^{*}
$$

Considering that the dividend-payout ratio should be a stationary variables the same cointegrating relationship up to a scale factor should hold between long-term interest rates and dividend yields and long-term interest rates and earning-yields. However, the existence of the same cointegrating relationship does not prevent the payout ratio from being an important factor in determining the short run dynamics of stock market prices. In fact, 
Lamont (1998) argues that the pay-out ratio helps to predict stock price fluctuations.

Some graphical evidence on the validity of the Graham-Dodd proposition for a sample of monthly data over the period 1980-1999 is reported in Figures $1-2$

\section{Insert Figure 1-2 here}

The time-series behaviour of the reported variables seems to be in line with the intuition that they share a common stochastic trend both for the US and the European case. Recent studies (Lander et al.(1997)) have chosen to construct an equilibrium by concentrating on long-term interest rates and the earning-price ratio. As a matter of fact the long-term interest rate features, over our sample, a much stronger co-movement with price-earning ratios than the short-term interest rate. Such evidence can be rationalized by considering that the long-term interest rates contains an element of risk premium which is absent form the short-term interest rate. Studies concentrating on the relationship between the short-term interest rates and dividend or earning yields have found empirical evidence for a sizeable and strongly persistent risk premium (see Blanchard(1983) and Wadhwani(1998)) which causes a rather weak long-run relationships among these variables. Our choice finds some empirical support in the correlation between the spread of long-term interest rates on short term interest rates and empirical mesures of risk premium based on the dividend models. Wadwhani derives a measure of risk premium by solving (11)at the steady state. At the steady state we have

$$
r_{t+i}=\bar{r}, g_{t+i}=\bar{g}
$$

and:

$$
\left(\frac{P}{D}\right)^{s s}=\frac{1}{\bar{r}-\bar{g}}=\frac{1}{r r+r p-\bar{g}}
$$

from which, it follows

$$
\left(\frac{D}{P}\right)^{s s} \simeq r r+r p-\bar{g}
$$


where $r r$ is the real short-term interest rate and $r p$ is th risk premium required to hold shares. Formula(14)is used to assess the level of risk-premium implied in the observed dividend yields by assuming a steady-state growth for earnings (say the real potential rate of growth of the economy, 2.5 per cent in the case of the US), and plugging in the real ex-post short term interest rate and the observed dividend-yields. In Figure 3-4 we report the time-series behaviour of $r p$ and the term spread between the yield on ten-year government bonds and the three-month interest rate for the US and european cases.

\section{Insert Figures 3-4 here}

We therefore concentrate on long-term interest rates and we choose to look at long-term interest rates and the earning-price ratio, following Lander et al.(1997), as, over our sample, the long term interest rates are statistically more closely related to price/earning ratios than to dividend/yields.

We take the following VAR specification as our baseline statistical model:

$$
\left(\begin{array}{c}
L P_{U S, t} \\
L E_{U S, t} \\
R_{U S, t} \\
L P_{E U, t} \\
L E_{E U, t} \\
R_{G e r, t}
\end{array}\right)=\mathbf{A}_{0}+\sum_{i=1}^{4} \mathbf{A}_{i}\left(\begin{array}{c}
L P_{U S, t-i} \\
L E_{U S, t-i} \\
R_{U S, t-i} \\
L P_{E U, t-i} \\
L E_{E U, t-i} \\
R_{G e r, t-i}
\end{array}\right)+\left(\begin{array}{c}
e_{1 t} \\
e_{2 t} \\
e_{3 t} \\
e_{4 t} \\
e_{5 t} \\
e_{6 t}
\end{array}\right)
$$

where $L P_{U S}$ and $L P_{E U}$ are the logs of the share price indexes for the US and for Europe, $L E_{U S}$ and $L E_{E U}$ are the logs of I/B/E/S analysts forecasts of earnings for the US and Europe, $R_{U S}$ and $R_{G e r}$ are the yields to maturity for US and German ten-year benchmark bonds. All the data are at monthly frequencies (end of period observations) and are taken from DATASTREAM. The VAR is estimated over the sample 1980:5- 1999:9, as data on benchmark bonds are available only from the beginning of the eighties onwards. The choice of length of the distributed lag has been based on the traditional likelihood based criteria. It is interesting to note that, when residuals are analyzed by using the diagnostic tests for normality, heteroscedasticity and autocorrelation proposed by the LSE methodology (see Hendry 1995), a strong evidence for non-normality emerges. We report in Table 1 tests for the null of normality of residuals at the single equation level and at the system level proposed by Doornik and Hansen(1994 ) and automatically implemented in the package PC-FIML (see Doornik and Hendry(1997)). 
TABLE 1: Testing residuals normality in the VAR system

\begin{tabular}{cccc}
\hline \hline$L P_{U S, t}$ & $L E_{U S, t}$ & $R_{U S, t}$ & $L P_{E U, t}$. \\
\hline$\chi_{2}^{2}=39.24^{* *}$ & $\chi_{2}^{2}=99.05^{* *}$ & $\chi_{2}^{2}=0.68$ & $\chi_{2}^{2}=2.84$ \\
\hline$L E_{E U, t}$ & $R_{E U, t}$ & System & \\
\hline$\chi_{2}^{2}=37.91^{* *}$ & $\chi_{2}^{2}=26.5^{* *}$ & $\chi_{12}^{2}=247.72^{* *}$ & \\
\hline
\end{tabular}

The null of normality is rejected at the one per cent confidence level for all the equations in the system except those for the US yield on benchmark bonds and the European share price index. As a consequence the null of normality of the distribution of the vector of VAR residuals is also strongly rejected. These diagnostic tests, which are in general important to detect misspecification and to ensure validity of inference, take additional importance in the context of our interest. In fact, non-normality is possibly determined by the presence of outliers, capturing the occurrences of those periods of turmoils crucial for the detection of contagion. To ensure congruency of our statistical model and to be able to exploit the information contained in the period of turmoils we proceed to include in our specification a number of point dummies. More precisely, we use an automatic criteria and construct a step dummy (taking a value 1 for the relevant observation and zero everywhere else) for each estimated residual more distant from zero than 2.5 times the standard deviation of estimated residuals. We report in Table 2 the significance of the selected dummies in each equation and their impact on normality of residuals 
TABLE 2: Removing outliers from the VAR system

\begin{tabular}{|c|c|c|c|c|c|c|}
\hline DUMMY & $L P_{U S, t}$ & $L E_{U S, t}$ & $\overline{R_{U S, t}}$ & $L P_{E U, t} \cdot$ & $L E_{E U, t}$ & $R_{E U, t}$ \\
\hline$\overline{D U M} M 102$ & $\begin{array}{l}0.022 \\
(0.037)\end{array}$ & $\begin{array}{l}0.003 \\
(0.014)\end{array}$ & $\begin{array}{l}0.56 \\
(0.43)\end{array}$ & $\begin{array}{l}-0.006 \\
(0.044)\end{array}$ & $\begin{array}{l}0.048 \\
(0.042)\end{array}$ & $\begin{array}{l}1.23 \\
(0.24)\end{array}$ \\
\hline DUM8106 & $\begin{array}{c}-0.032 \\
(0.037)\end{array}$ & $\begin{array}{l}0.033 \\
(0.014)\end{array}$ & $\begin{array}{l}0.89 \\
(0.42)\end{array}$ & $\begin{array}{l}-0.04 \\
(0.044)\end{array}$ & $\begin{array}{c}-\mathbf{0 . 1 6} \\
(0.042)\end{array}$ & $\begin{array}{c}-0.10 \\
(0.24)\end{array}$ \\
\hline$\overline{D U M} M 503$ & $\begin{array}{c}-0.031 \\
(0.036)\end{array}$ & $\begin{array}{l}-0.018 \\
(0.014)\end{array}$ & $\begin{array}{c}-0.34 \\
(0.42)\end{array}$ & $\begin{array}{l}0.031 \\
(0.044)\end{array}$ & $\begin{array}{l}\mathbf{0 . 2 2} \\
(0.042)\end{array}$ & $\begin{array}{c}-0.22 \\
(0.23)\end{array}$ \\
\hline DUM8701 & $\begin{array}{c}\mathbf{0 . 1 2} \\
(0.036)\end{array}$ & $\begin{array}{l}0.003 \\
(0.013)\end{array}$ & $\begin{array}{l}0.01 \\
(0.41)\end{array}$ & $\begin{array}{c}-0.006 \\
(0.044)\end{array}$ & $\begin{array}{l}0.084 \\
(0.041)\end{array}$ & $\begin{array}{c}-0.31 \\
(0.23)\end{array}$ \\
\hline DUM8710 & $\begin{array}{c}\mathbf{- 0 . 2 2} \\
(0.037)\end{array}$ & $\begin{array}{c}-0.004 \\
(0.014)\end{array}$ & $\begin{array}{c}-0.66 \\
(0.42)\end{array}$ & $\begin{array}{c}\mathbf{0 . 1 5} \\
(0.044)\end{array}$ & $\begin{array}{l}0.078 \\
(0.042)\end{array}$ & $\begin{array}{c}-0.53 \\
(0.24)\end{array}$ \\
\hline DUM8806 & $\begin{array}{c}-0.0003 \\
(0.036)\end{array}$ & $\begin{array}{c}\mathbf{0 . 0 3 9} \\
(0.013)\end{array}$ & $\begin{array}{c}-0.31 \\
(0.41)\end{array}$ & $\begin{array}{c}-0.031 \\
(0.044)\end{array}$ & $\begin{array}{c}-0.039 \\
(0.04)\end{array}$ & $\begin{array}{c}0.004 \\
(0.23)\end{array}$ \\
\hline$\overline{D U M} M 910$ & $\begin{array}{c}-0.0362 \\
(0.037)\end{array}$ & $\begin{array}{c}\mathbf{0 . 0 3 7} \\
(0.013)\end{array}$ & $\begin{array}{c}-0.52 \\
(0.41)\end{array}$ & $\begin{array}{c}-0.031 \\
(0.044)\end{array}$ & $\begin{array}{c}0.027 \\
(0.04)\end{array}$ & $\begin{array}{l}0.12 \\
(0.23)\end{array}$ \\
\hline DUM9002 & $\begin{array}{c}0.0024 \\
(0.036)\end{array}$ & $\begin{array}{c}-0.004 \\
(0.013)\end{array}$ & $\begin{array}{l}0.15 \\
(0.42) \\
\end{array}$ & $\begin{array}{l}-0.06 \\
(0.043) \\
\end{array}$ & $\begin{array}{c}-0.059 \\
(0.041)\end{array}$ & $\begin{array}{l}\mathbf{1 . 1 6} \\
(0.23)\end{array}$ \\
\hline DUM9112 & $\begin{array}{c}\mathbf{0 . 0 8 2} \\
(0.036)\end{array}$ & $\begin{array}{l}-0.007 \\
(0.013)\end{array}$ & $\begin{array}{c}-0.44 \\
(0.41)\end{array}$ & $\begin{array}{l}0.06 \\
(0.043)\end{array}$ & $\begin{array}{l}0.058 \\
(0.041)\end{array}$ & $\begin{array}{c}-0.12 \\
(0.23)\end{array}$ \\
\hline DUM9201 & $\begin{array}{c}-0.021 \\
(0.036) \\
\end{array}$ & $\begin{array}{c}\mathbf{0 . 0 8 1} \\
(0.013)\end{array}$ & $\begin{array}{l}0.81 \\
(0.41) \\
\end{array}$ & $\begin{array}{c}0.01 \\
(0.043) \\
\end{array}$ & $\begin{array}{c}-0.045 \\
(0.041) \\
\end{array}$ & $\begin{array}{l}0.14 \\
(0.23) \\
\end{array}$ \\
\hline DUM9701 & $\begin{array}{l}0.033 \\
(0.037) \\
\end{array}$ & $\begin{array}{c}\mathbf{0 . 0 5 1} \\
(0.013) \\
\end{array}$ & $\begin{array}{c}-0.04 \\
(0.41) \\
\end{array}$ & $\begin{array}{l}-0.01 \\
(0.043) \\
\end{array}$ & $\begin{array}{l}0.064 \\
(0.040) \\
\end{array}$ & $\begin{array}{c}-0.004 \\
(0.23) \\
\end{array}$ \\
\hline DUM9808 & $\begin{array}{c}-\mathbf{0 . 1 2 5} \\
(0.035) \\
\end{array}$ & $\begin{array}{c}-0.0005 \\
(0.013)\end{array}$ & $\begin{array}{c}-0.33 \\
(0.41)\end{array}$ & $\begin{array}{c}-\mathbf{0 . 1 4 7} \\
(0.043)\end{array}$ & $\begin{array}{l}0.025 \\
(0.041) \\
\end{array}$ & $\begin{array}{c}-0.34 \\
(0.23) \\
\end{array}$ \\
\hline DUM9810 & $\begin{array}{c}\mathbf{0 . 0 7} \\
(0.038) \\
\end{array}$ & $\begin{array}{l}0.017 \\
(0.014) \\
\end{array}$ & $\begin{array}{l}1.11 \\
(0.44) \\
\end{array}$ & $\begin{array}{l}\mathbf{0 . 0 9} \\
(0.045) \\
\end{array}$ & $\begin{array}{c}-0.023 \\
(0.044) \\
\end{array}$ & $\begin{array}{l}0.78 \\
(0.24) \\
\end{array}$ \\
\hline$\sigma$ & 0.013 & 0.03 & 0.39 & 0.041 & 0.039 & 0.22 \\
\hline Test $\chi_{2}^{2}$ & 2.22 & $18.7^{* *}$ & 3.75 & 1.46 & 6.47 & 0.4 \\
\hline System $\chi_{12}^{2}$ & 36.98 & & & & & \\
\hline
\end{tabular}

We note that the introduction of dummies removes non-normality from all the equations with the only exception of that for US earnings, which in turn causes entirely system non-normality. As such non-normality is not attributable to specific large outliers but to a consistent number of outliers of moderate dimension and it does not have any effect on the normality of residuals from the equation for share prices, we do not add any further dummies. We have identified five periods of US stock market turmoils:in 1987:10 and 1998:10 we have downward corrections respectively of twenty-two and twelve per cent, while in 1987:01, 1991:12, and 1998:10 we have upward movements of twelve, eight and seven per cent. Interestingly, downward sudden corrections in the US market are always paired with abnormal movements in 
the same direction of the European market, while, in the case of upward movements, we observe a synchronous response only in 1998:10. Note that this evidence, coming from a reduced form, cannot be decisive on the issue of contagion versus interdependence. In fact, evidence of contagion can be provided only within structural models modelling simultaneous feedback.

We then control for outliers and consider the following VAR as the baseline statistical model for our investigation:

$$
\left(\begin{array}{c}
L P_{U S, t} \\
L E_{U S, t} \\
R_{U S, t} \\
L P_{E U, t} \\
L E_{E U, t} \\
R_{G e r, t}
\end{array}\right)=\mathbf{A}_{0}+\sum_{i=1}^{4} \mathbf{A}_{i}\left(\begin{array}{c}
L P_{U S, t-i} \\
L E_{U S, t-i} \\
R_{U S, t-i} \\
L P_{E U, t-i} \\
L E_{E U, t-i} \\
R_{G e r, t-i}
\end{array}\right)+\mathbf{B} * \mathbf{D U M}+\left(\begin{array}{c}
e_{1 t} \\
e_{2 t} \\
e_{3 t} \\
e_{4 t} \\
e_{5 t} \\
e_{6 t}
\end{array}\right)
$$

where DUM. is a vector of dummies containing DUM8102, DUM8106, DUM8503, DUM8701, DUM8710, DUM8806, DUM8910, DUM9002, DUM9112, DUM9201, DUM9701, DUM9808, DUM9810. The generic dummy DUMmmyy takes value one in month mm of year yy and zero anywhere else.

\section{Measuring long-run interdependence between US and European stock markets}

Equipped with model (16), we address the first issue of our interest: long-run interdependence between US and European stock markets.

Figure 1 and 2 seem to support the evidence that there are two equilibrium relationships among our variables, one linking the US long-term interest rates to the US price/earning ratio and the other one linking the German longterm interest rates to the European price/earning ratio. Such hypothesis can be parameterized in our VAR using the Johansen(1995) approach to cointegration. Re-parameterize (16) as follows: 


$$
\begin{aligned}
\left(\begin{array}{c}
\Delta L P_{U S, t} \\
\Delta L E_{U S, t} \\
\Delta R_{U S, t} \\
\Delta L P_{E U, t} \\
\Delta L E_{E U, t} \\
\Delta R_{G e r, t}
\end{array}\right)= & \mathbf{A}_{0}+\sum_{i=1}^{3} \Pi_{i}\left(\begin{array}{c}
\Delta L P_{U S, t-i} \\
\Delta L E_{U S, t-i} \\
\Delta R_{U S, t-i} \\
\Delta L P_{E U, t-i} \\
\Delta L E_{E U, t-i} \\
\Delta R_{G e r, t-i}
\end{array}\right)+\Pi\left(\begin{array}{c}
L P_{U S, t-1} \\
L E_{U S, t-1} \\
R_{U S, t-1} \\
L P_{E U, t-1} \\
L E_{E U, t-1} \\
R_{G e r, t-1}
\end{array}\right)+ \\
& +\mathbf{B} * \mathbf{D U M}_{t}+\left(\begin{array}{c}
e_{1 t} \\
e_{2 t} \\
e_{3 t} \\
e_{4 t} \\
e_{5 t} \\
e_{6 t}
\end{array}\right) \\
\Pi_{i}= & -\left(I-\sum_{j=1}^{i} \mathbf{A}_{j}\right) \\
\Pi= & -\left(I-\sum_{i=1}^{3} \mathbf{A}_{i}\right)
\end{aligned}
$$

where the matrix $\Pi$ describes the long-run properties of our system. Under the null of our interest there are two equilibria relationships, therefore the rank of $\Pi$ is two. In this case we have

$$
\begin{aligned}
& \Pi=\boldsymbol{\alpha} \boldsymbol{\beta}^{\prime} \\
& \alpha=\left(\begin{array}{ll}
\alpha_{11} & \alpha_{12} \\
\alpha_{21} & \alpha_{22} \\
\alpha_{31} & \alpha_{32} \\
\alpha_{41} & \alpha_{42} \\
\alpha_{51} & \alpha_{52} \\
\alpha_{61} & \alpha_{62}
\end{array}\right), \beta=\left(\begin{array}{ll}
\beta_{01} & \beta_{02} \\
\beta_{11} & \beta_{12} \\
\beta_{21} & \beta_{22} \\
\beta_{31} & \beta_{32} \\
\beta_{41} & \beta_{42} \\
\beta_{51} & \beta_{52} \\
\beta_{61} & \beta_{62}
\end{array}\right)
\end{aligned}
$$

where the parameters in $\boldsymbol{\beta}^{\prime}$ determine the equilibrium relationships, on which the Graham-Dodd theory imposes further restrictions. In fact, under such theory the $\beta$ matrix takes the following form: 


$$
\beta=\left(\begin{array}{cc}
\beta_{01} & \beta_{02} \\
1 & 0 \\
-1 & 0 \\
\beta_{31} & 0 \\
0 & 1 \\
0 & -1 \\
0 & \beta_{62}
\end{array}\right)
$$

The first coefficient in each cointegrating vector captures the value of the constant, which we have restricted to belong to the cointegrating space ${ }^{1}$. Johansen (1995) shows how such restrictions over-identify the cointegrating space and therefore they are also testable.

In Table 3 we provide the sequence of estimated eigenvalues of the longrun matrix along with the test for the rank of $\Pi$ based on the trace-statistic implemented in PC-FIML (see, Doornik and Hendry(1997).

TABLE 3: Analysis of the $\Pi$ matrix in the VAR model

\begin{tabular}{cccc}
\hline \hline Eigenvalue & $\mathrm{H}_{0}:$ rank $=r$ & Trace & $95 \%$ \\
\hline 0.18 & $p=0$ & $123.9^{* *}$ & 102.1 \\
0.11 & $p \leq 1$ & $77.9^{*}$ & 76.1 \\
0.078 & $p \leq 2$ & 51.2 & 53.1 \\
\hline 0.066 & $p \leq 3$ & 32.04 & 34.9 \\
\hline 0.042 & $p \leq 4$ & 16.2 & 20.0 \\
\hline 0.025 & $p \leq 5$ & 6.03 & 9.2 \\
\hline
\end{tabular}

The hypothesis of at most one cointegrating vector is rejected at the 95 per cent statistical level while the hypothesis of at most two cointegrating vectors is not rejected at the 95 per cent statistical level. We consider this evidence in line with the hypothesis of two equilibria for the US and European market and proceed to the test of the overidentifying restrictions implicit in the Graham-Dodd hypothesis.

The restricted cointegration analysis delivers the following estimates (with standard errors within brackets) for the parameters in the $\alpha$ and $\beta$ matrices

\footnotetext{
${ }^{1}$ Given the nature of our time series we have opted for omitting deterministic trends from our VAR
} 


$$
\Pi=\alpha \beta^{\prime}=\left(\begin{array}{cc}
-0.026 & -0.037 \\
(0.0056) & (0.016) \\
-0.0015 & 0.013 \\
(0.002) & (0.006) \\
0.012 & -0.28 \\
(0.065) & (0.19) \\
-0.021 & -0.026 \\
(0.006) & (0.02) \\
-0.006 & 0.019 \\
(0.006) & (0.02) \\
0.0067 & -0.10 \\
(0.037) & (0.10)
\end{array}\right)\left(\begin{array}{ccccccc}
-5.11 & 1 & -1 & 0.20 & 0 & 0 & 0 \\
(0.35) & & & (0.035) & & \\
-3.51 & 0 & 0 & 0 & 1 & -1 & 0.15 \\
(0.21) & & & & & & (0.026)
\end{array}\right)
$$

The likelihood ratio test of overidentifying, distributed as a $\chi_{6}^{2}$, takes a value of 15.48. On the basis of the observed statistic the null is not rejected at the one per cent level, such level raises above the five per cent when a small sample correction is applied. On the basis of this evidence we cannot reject the null of no long-run interdependence between the US and the European stock markets. Note that the estimates of the adjustment parameters in $\alpha$ give support to the hypothesis that, in presence of disequilibria, the adjustment occurs on share prices. In fact, the only significant weights on the cointegrating vectors are those in the equations for share prices. Interestingly share prices in Europe and the US seem to react both to own and foreign disequilibria, however this is a short-run phenomenon and we shall re-consider this issue when discussing short-run interdependence. We conclude this section by reporting in Figure 3 disequilibria for the US and European markets

\section{Insert Figure 5 here}

The analysis of the time-series behaviour of disequilibria shows that in 1999 the US stock market prices exceeds their equilibrium values by about twenty per cent, such overvaluation is comparable with that observed before the 1987 crash.

We also note that there is no close relationship among disequilibria, in fact they are mildly positively correlated, with a correlation coefficient of 0.23 . 


\section{$5 \quad$ Measuring short-run interdependence and contagion between US and European stock markets}

To model short-run interdependence and assess contagion we need a structure. We build it starting from simplifying the baseline statistical model into a bivariate Vector Error Correction model for US and European share prices, where long-term interest rates and earnings are taken as exogenous :

$$
\begin{aligned}
\left(\begin{array}{c}
\Delta L P_{U S, t} \\
\Delta L P_{E U, t}
\end{array}\right)= & \mathbf{B}_{0}+\sum_{i=1}^{3} \mathbf{B}_{i}\left(\begin{array}{c}
\Delta L P_{U S, t-i} \\
\Delta L P_{E U, t-i}
\end{array}\right)+\sum_{i=0}^{3} \mathbf{C}_{i}\left(\begin{array}{c}
\Delta R_{U S, t-i} \\
\Delta R_{G e r, t-i} \\
\Delta L E_{U S, t-i} \\
\Delta L E_{E U, t-i}
\end{array}\right)+\quad(18) \\
& +\mathbf{D}\left(\begin{array}{c}
L P_{U S, t-1}-L P_{U S, t-1}^{*} \\
L P_{E U, t-1}-L P_{E U, t-1}^{*}
\end{array}\right)+\mathbf{F}\left(\begin{array}{c}
d u m 8701 \\
d u m 8710 \\
d u m 9112 \\
d u m 9808 \\
d u m 9810
\end{array}\right)+\left(\begin{array}{l}
u_{1 t} \\
u_{2 t}
\end{array}\right), \\
L P_{U S, t-1}^{*}= & L E_{U S, t-1}-0.20 R_{U S, t-1}+5.11, \\
L P_{E U, t-1}^{*}= & L E_{E U, t-1}-0.15 R_{G e r, t-1}+3.51 .
\end{aligned}
$$

The specification of (18) is based on the results of our cointegration analysis. In fact we have used estimated cointegrating parameters to define equilibria, and we have used the statistical results on the weights in the matrix $\alpha$ to attribute exogeneity status to long-term interest rates and earnings. Our long-run analysis shows that only share prices adjusts significantly in presence of disequilibrium, Johansen(1995) illustrates how this result can be considered in our case as evidence of exogeneity of long-term interest rates and earnings for the estimation of parameters of interest in a model for share prices. Finally we have kept in the specification only those dummies necessary to remove outliers in the dependent variables. Diagnostic tests ${ }^{2}$, reported in Table 4, show that the null of absence of residuals correlation, homoscedasticity and normality cannot be rejected for (18) .

\footnotetext{
${ }^{2}$ All the tests have performed at system level using PC-FIML, for a detailed description see Doornik-Hendry(1997)
} 
TABLE 4: Testing congruency of (18)

\begin{tabular}{ccl}
\hline \hline Normality & Autocorrelation 1-7 & Omoscedasticity \\
\hline$\chi_{4}^{2}=3.23(0.52)$ & $F(28,378)=1.2(0.22)$ & $F(156,447)=0.43(0.67)$ \\
\hline
\end{tabular}

On the basis of this reduced form, we proceed to estimate two structures. A more general structure allows for both short-run interdependence and contagion, while a more restrictive one is consistent with the hypothesis of "only interdependence, no contagion". Both structures impose some testable overidentifying restrictions on our reduced form and we can therefore use the outcome of the tests to discriminate between the cases of interest. The estimated structural models are reported in Table 5-6.(19) - (20) reported in Table 5 is consistent with the hypothesis of the existence of contagion between the US and European stock markets. In fact in the case of interdependence only, when a simultaneous feedback is allowed from US to European stock markets, the dummies capturing turmoil periods in the US market should not enter significantly the equation for European stock prices. We observe that not only such dummies enter significantly but also that their inclusion renders the simultaneous feedback between European and US stock markets not significantly different from zero. Importantly, the model is supported by the data in that the tests for the validity of the thirty-seven over-identifying restrictions imposed by (19) - (20) on the general reduced form (18) does not lead to the rejection of the null hypothesis of interest.

It is interesting to estimate, over the same sample and with the same method, the structure implicit in the hypothesis of no contagion only interdependence. The results from estimation are reported in Table 6. The validity of over-identifying restrictions is now rejected, consistently the test proposed in the previous sections rejects the null of no contagion at the one per cent level. As we have four dummies our test for the null of no-contagion is distributed as a $\chi_{4}^{2}$. Interestingly, as a consequence of the omission of dummies, the significance of the simultaneous feedback increases drastically and might mislead the inference if the specific model (21) - (22) is estimated without reference to the general model $(19)-(20)$. 
TABLE 5: Modelling interdependence and contagion between US and European markets,

estimation by FIML over the sample 1980:5-1999:9:

$$
\begin{aligned}
& \Delta L P_{U S, t}=\underset{(0.007)}{0.0007}-\underset{(0.008)}{\mathbf{0 . 0 2 4}}\left(L P_{U S, t-1}-L P_{U S, t-1}^{*}\right)-\underset{(0.014)}{\mathbf{0 . 0 4}}\left(L P_{E U, t-1}-L P_{E U, t-1}^{*}\right) \\
& -\underset{(0.005)}{\mathbf{0 . 0 3 7}} \Delta R_{U S, t}+\underset{(0.10)}{0.18 \Delta L E_{U S, t}}-\underset{(0.04)}{\mathbf{0 . 1 2}} \Delta L E_{E U, t} \\
& +\underset{(0.03)}{\mathbf{0 . 1 3}} d u m 8701-\underset{(0.03)}{\mathbf{0 . 2 5}} d u m 8710 \\
& -\underset{(0.03)}{\mathbf{0 . 1 3}} d u m 9808+\underset{(0.03)}{\mathbf{0 . 1 0}} d u m 9810+\hat{e}_{1 t} \\
& \Delta L P_{E U, t}=\underset{(0.008)}{0.003}+\underset{(0.045)}{\mathbf{0 . 0 9 6} \Delta L P_{E U, t-1}}-\underset{(0.018)}{0.034}\left(L P_{E U, t-1}-L P_{E U, t-1}^{*}\right) \\
& -\underset{(0.01)}{0.013}\left(L P_{U S, t-1}-L P_{U S, t-1}^{*}\right)-\underset{(0.008)}{\mathbf{0 . 0 5 9}} \Delta R_{G e r, t}+\underset{(0.05)}{\mathbf{0 . 3 5} \Delta L E_{E U, t}} \\
& +\underset{(0.16)}{0.07} \Delta L P_{U S, t}-\underset{(0.04)}{0.065} d u m 8701-\underset{(0.054)}{\mathbf{0 . 2 0}} \mathrm{dum} 8710 \\
& -\underset{(0.04)}{\mathbf{0 . 1 6}} d u m 9808+\underset{(0.04)}{\mathbf{0 . 1 3}} d u m 9810+e_{2 t} \\
& L P_{U S, t}^{*}=L E_{U S, t-1}-0.20 R_{U S, t-1}-5.1 \\
& L P_{E U, t}^{*}=L E_{E U, t-1}-0.15 R_{G e r, t-1}-3.5
\end{aligned}
$$

Test of validity of over-identifying restrictions : $\chi_{37}^{2}=40.993$ [0.2997] 
TABLE 6: Testing the null of no contagion interdependence only between US and European markets,

estimation by FIML over the sample 1980:5-1999:9:

$$
\begin{aligned}
& \Delta L P_{U S, t}=\underset{(0.007)}{0.0007}-\underset{(0.008)}{\mathbf{0 . 0 2 4}}\left(L P_{U S, t-1}-L P_{U S, t-1}^{*}\right)-\underset{(0.014)}{\mathbf{0 . 0 4}}\left(L P_{E U, t-1}-L P_{E U, t-1}^{*}\right) \\
& -\underset{(0.005)}{\mathbf{0 . 0 3 7}} \Delta R_{U S, t}+\underset{(0.10)}{0.16} \Delta L E_{U S, t}-\underset{(0.04)}{\mathbf{0 . 1 2}} \Delta L E_{E U, t} \\
& +\underset{(0.03)}{\mathbf{0 . 1 3}} d u m 8701-\underset{(0.03)}{\mathbf{0 . 2 5}} d u m 8710 \\
& -\underset{(0.03)}{\mathbf{0 . 1 3}} d u m 9808+\underset{(0.03)}{\mathbf{0 . 1 0}} d u m 9810+\hat{e}_{1 t} \\
& \Delta L P_{E U, t}=\underset{(0.008)}{0.003}+\underset{(0.049)}{\mathbf{0 . 0 9 1}} \Delta L P_{E U, t-1}-\underset{(0.018)}{0.021}\left(L P_{E U, t-1}-L P_{E U, t-1}^{*}\right) \\
& -\underset{(0.01)}{0.0042}\left(L P_{U S, t-1}-L P_{U S, t-1}^{*}\right)-\underset{(0.009)}{\mathbf{0 . 0 3 8} \Delta R_{G e r, t}}+\underset{(0.05)}{\mathbf{0 . 3 5} \Delta L E_{E U, t}}
\end{aligned}
$$

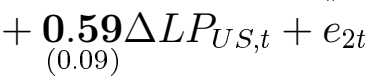

$$
\begin{aligned}
& L P_{U S, t}^{*}=L E_{U S, t-1}-0.20 R_{U S, t-1}-5.1 \\
& L P_{E U, t}^{*}=L E_{E U, t-1}-0.15 R_{G e r, t-1}-3.5
\end{aligned}
$$

Test of validity of over-identifying restrictions : $\chi_{41}^{2}=83.53[0.0001]^{* *}$ Test of the null of no-contagion : $\chi_{4}^{2}=21.66[0.0001]^{* *}$ 
To allow comparison of our results with the IV based approach we have created an instrument $w_{t}$, which is equal to $-\Delta L P_{U S, t} / 240$ for all observations in our sample except for 1987:1, 1987:10, 1998:08, 1998:10, where it is equal to $\Delta L P_{U S, t} / 4$. The sample correlation between $\Delta L P_{U S, t}$ and $w_{t}$ is of 0.53 . We have then proceeded to test the validity of such instrument by implementing an Hausman(1978) test. The augmented regression, estimated by IV is reported in Table 7

TABLE 7 : Testing contagion with the IV approach

$$
\begin{aligned}
& \Delta L P_{E U, t}=\underset{(0.003)}{0.005}+\underset{(0.049)}{\mathbf{0 . 0 9 1}} \Delta L P_{E U, t-1}-\underset{(0.012)}{0.024}\left(L P_{E U, t-1}-L P_{E U, t-1}^{*}\right) \\
& +\underset{(0.01)}{0.004}\left(L P_{U S, t-1}-L P_{U S, t-1}^{*}\right)-\underset{(0.009)}{\mathbf{0 . 0 4 6}} \Delta R_{G e r, t}+\underset{(0.05)}{\mathbf{0 . 3 3} \Delta L E_{E U, t}} \\
& +\underset{(0.11)}{\mathbf{0 . 7 9}} \Delta L P_{U S, t}-\underset{(0.13)}{\mathbf{0 . 3 4}} \hat{u_{t}}+\hat{e}_{2 t}
\end{aligned}
$$

additional instrum ents : $\Delta R_{U S, t}, \Delta L E_{U S, t}, D U M 8701, D U M 8710, D U M 9808, D U M 9810$

$u_{t}$ are the residuals of the regression of $\Delta L P_{U S, t}$ on $w_{t}$

As the coefficient on $u_{t}$ is significantly different from zero, the null of nocontagion is rejected and our results are confirmed by the implementation of the IV procedure.

\section{Contagion and the response of European stock market to a correction in the US.}

The results reported in the previous section point clearly toward a non-linear model of short-run interdependence between the two areas. In fact, there seems to be a threshold effect in the impact of short-run US stock market fluctuations in Europe: for value below 2.5 times the standard error of the equation for US stock prices there is a small and not significant impact on European stock market; such impact increases drastically when fluctuations are higher then the threshold. The standard error of our estimated equation for US share prices implies a value for the threshold of an eight per cent 
monthly fluctuation of US share prices. Such effect, which defines contagion, is precisely measured within a non-linear model. To illustrate the point we have estimated over the sample 1980:5-1999:9, by Non-Linear Two-Stage Least Squares $^{3}$, a simple non-linear specification for European stock market fluctuations. The results are reported in Table 8:

TABLE 8: A non-linear specification for the European stock market

$$
\begin{aligned}
& \Delta L P_{E U, t}=\underset{(0.008)}{0.003}+\underset{(0.045)}{\mathbf{0 . 1 0} \Delta L P_{E U, t-1}}-\underset{(0.018)}{0.035}\left(L P_{E U, t-1}-L P_{E U, t-1}^{*}\right) \\
& -\underset{(0.01)}{0.013}\left(L P_{U S, t-1}-L P_{U S, t-1}^{*}\right)-\underset{(0.01)}{\mathbf{0 . 0 6 2} \Delta R_{G e r, t}}+\underset{(0.05)}{\mathbf{0 . 3 5} \Delta L E_{E U, t}} \\
& +\underset{(0.18)}{(0.04}-\underset{(0.31)}{0.47} \mathrm{dum} 8701+\underset{(0.23)}{\mathbf{0 . 8 6}} \mathrm{dum} 8710 \\
& +\underset{(0.37)}{\mathbf{1 . 4 2}} \operatorname{dum} 9808+\underset{(0.33)}{\mathbf{1 . 1 0}} d u m 9810) * \Delta L P_{U S, t}+\hat{e}_{2 t}
\end{aligned}
$$

Interestingly, parameters capturing the non-linear effect of US stock price fluctuations can be restricted to one when significant, moreover the evidence is unequivocal for downward corrections while it is mixed for upward movements. . To illustrate the implications of contagion effect we use the nonlinear specification for Europe together with the linear model for the US to simulate the impact of a twenty four per cent downward correction in US stock market. We simulate a non-linear model with a threshold set at eight per cent. Monthly fluctuations of the US stock market smaller than eight per cent have a null simultaneous impact on the European market, while such impact increases to unity for fluctuations higher than eight per cent. We consider two scenarios: a sudden correction of 24 per cent within a month, and a gradual correction, where the same movement occurs in four month. We compute dynamic multipliers by shocking the model in 1982:8, a period where the disequilibrium in the US stock market was close to the one currently observed, and leaving paths for all exogenous variables unaltered. Dynamic multipliers ${ }^{4}$ associated to the two different scenarios, reported in

\footnotetext{
${ }^{3}$ Our instruments are $\Delta L P_{E U, t-1},\left(L P_{E U, t-1}-L P_{E U, t-1}^{*}\right),\left(L P_{U S, t-1}-L P_{U S, t-1}^{*}\right)$,

$\Delta R_{U S, t}, \Delta R_{G e r, t}, \Delta L E_{U S, t}, \Delta L E_{E U, t}$, dum8701,dum8710,dum9808,dum9810

${ }^{4}$ Standard errors for the dynamic multipliers, computed on stochastic simulations are available upon request. They show that the multiplier on gradual adjustment never differs significantly from zero, while the multiplier on sudden adjustment does not differ significantly from one at the impact and differs significantly from zero for two years after the impact.
} 
Figure 6, show clearly the importance of non-linearity.

\section{Insert Figure 6 here}

A gradual correction in the US has virtually no short-run effect in Europe, while a sudden correction has a one-to-one impact on the European market. In the long-run all effects vanish has our model features no interdependence.

\section{Conclusions}

In this paper we have considered the linkages between US and European stock markets. We have assessed the relative importance of contagion and interdependence within the framework of an explicit structural model, using cointegration analysis to separate. long-run equilibria from short term dynamics. We have constructed our long-run equilibria by developing on a wellknown hypothesis put forward by Graham and Dodd, according to which the earning-price ratio and the long-term interest rates should be cointegrated. We have parameterized such hypothesis in a Vector Error Correction framework, and found evidence in favor of the Graham and Dodd hypothesis both for the US and European markets. Moreover, within such framework we found that the hypothesis of no long-run interdependence between the two markets cannot be rejected. In the long-run both markets are driven by domestic fundamentals. We have then used our VECM as a baseline reduced form and constructed a structural model to assess the relative importance of interdependence and contagion in determining the short-run dynamics of the two markets. Our structural model shows that fluctuations in the European market have no impact of the US market, while the effect of fluctuations of US stock market on the European stock market is captured by a non-linear specification. Fluctuations in the US stock market have virtually no effect on the European market when they are below the threshold of eight per cent on a monthly basis, such effect becomes one-to-one for downward fluctuations higher than the threshold, while the impact of upward fluctuations is more moderate. Such non-linearity is clearly consistent with the relevance of contagion, in that it amounts to a modification of short run interdependence in period of turmoils. Our results are confirmed by the application of the Instrumental Variable methodology proposed by Rigobon(2000). We believe that the specification of a structural model along the lines of the LSE strategy, minimizes the risks of mis-specification and allows naturally 
the identification of turmoil episodes crucial for assessing the relevance of contagion.

Finally, we show that the impact on European Stock market of a correction of 25 per cent in the US stock market can be very different. A gradual correction in the US stock market has virtually no impact on the European market, while a sudden correction has a one-to-one short-run effect with a rather persistent, but limited, memory. 


\section{References}

[1] Bertero E. and C. Mayer (1990) "Structure and performance: Global interdependence of stock markets around the crash of october 1987" European Economic Review, 34: 1155-80

[2] Blanchard O. (1993) "Movements in the Equity Premium" Brookings Paper on Economic Activity 75-135

[3] Bernanke B. and M.Gertler(1999) "Monetary policy and asset price volatility", paper presented at the Federal Reserve Bank of Kansas City conference on "New Challenges for Monetary Policy", Jackson Hole, Wyoming, August 1999

[4] Campbell, J. Lo, A. and McKinlay(1997) "The Econometrics of Financial Markets" Princeton University Press

[5] Doornik J. and D. F. Hendry. PcFIML 9.0. Interactive econometric modelling of dynamic systems. Thomson Publishing, Oxford, 1997.

[6] Doornik J., and H. Hansen. A practical test of multivariate normality. Nuffield College, Oxford, 1994.

[7] Favero C.A. and F.Giavazzi(2000) "Looking for contagion: the 1992 ERM crisis", mimeo IGIER, Università Bocconi

[8] Graham B. and D.L. Dodd(1962) "Security Analysis" , 4th edition, New York. Mc-Graw-Hill 1962

[9] Hausman J.(1978), "Specification tests in Econometrics" Econometrica, $76,1251-1271$

[10] Hendry D. F. Dynamic Econometrics. Oxford University Press, 1995

[11] King M. and S. Wadwhani (1990) "Transmission of volatility between stock markets" Review of Financial Studies, 3(1): 5-33.

[12] Johansen S. Likelihood Based Inference on Cointegration in the Vector Autoregressive Model. Oxford University Press, Oxford, 1995. 
[13] Lander J., Orphanides A. and M.Douvogiannis(1997) "Earning forecasts and the predictability of stock returns: evidence from trading the S\&P" Board of Governors of the Federal Reserve System, http: \\www.bog.frb.fed.org

[14] Lee S. B. and K. J. Kim (1993) "Does the october 1987 crash strengthen the co-movements among national stock markets?" Review of Financial Economics, 3(1): 89-102

[15] Longin F. and Solnik B.(1995) "Is the correlation in international equity returns constant:1960-1990?" Journal of International Money and Finance,14,1, 3-26

[16] Lamont O.(1998) "Earnings and expected returns" The Journal of Finance, $53,5,1563-1587$

[17] Rigobon R.(1999) "Identification through heteroscedasticity: measuring "contagion" between Argentinean and Mexican sovereign bonds" mimeo, MIT

[18] Rigobon R. (1999) "On the Measurement of the International Propagation of Shocks", downloadable form http://web.mit.edu/rigobon/www/

[19] Rigobon R, and K.Forbes(1999) "On the measurement of the International Propagation of shocks" mimeo, MIT

[20] Wadhwani S.(1998) "The US stock market and the global economic crisis", mimeo, Tudor Investment Corporation 


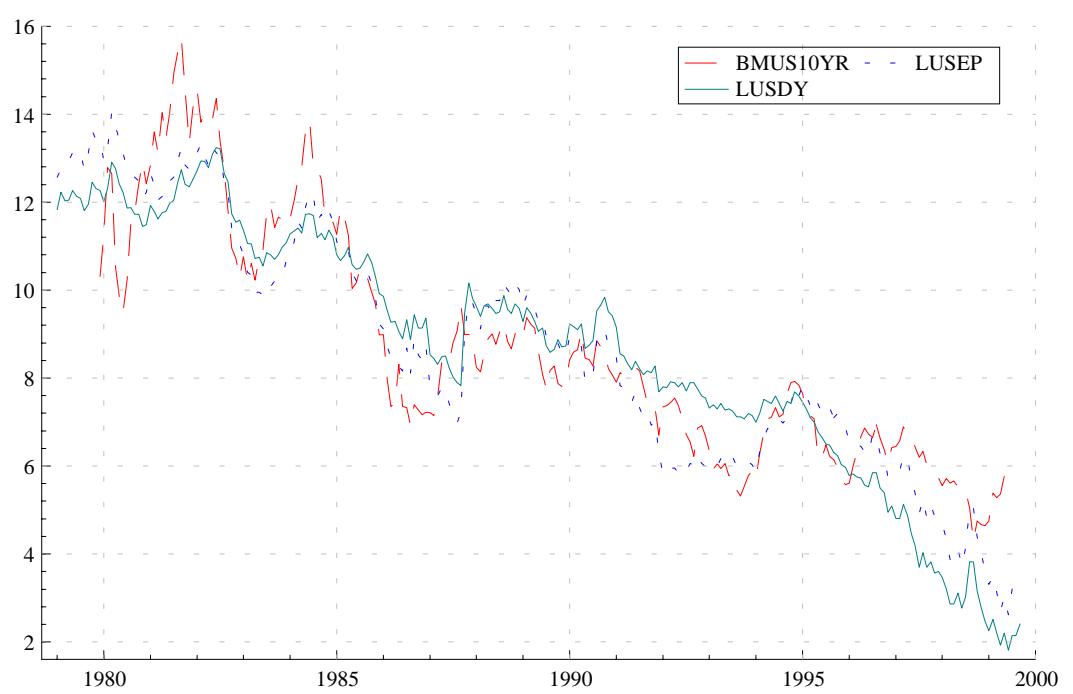

Figure 1: US long-term interest rates(BMUS10YR), (log of )dividend yield (LUSDY) and (log of) earning/price ratio(LUSEP)

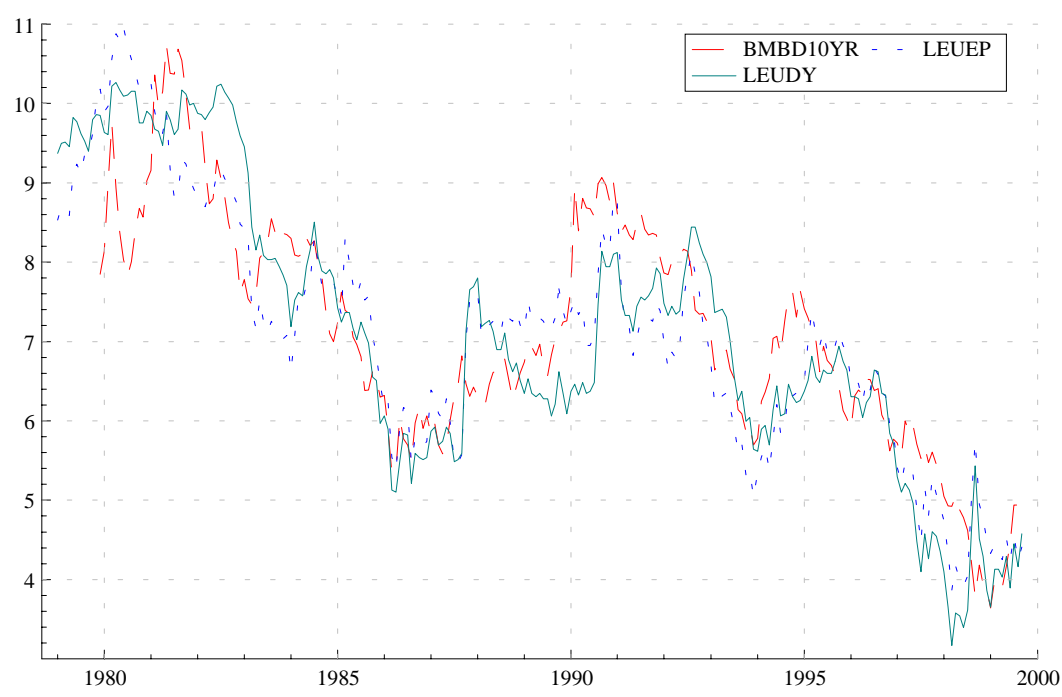

Figure 2: Europe long-term interest rates (German rate BMBD10YR), (log of ) dividend yield (LEUDY) and (log of) earning/price ratio(LEUEP). 


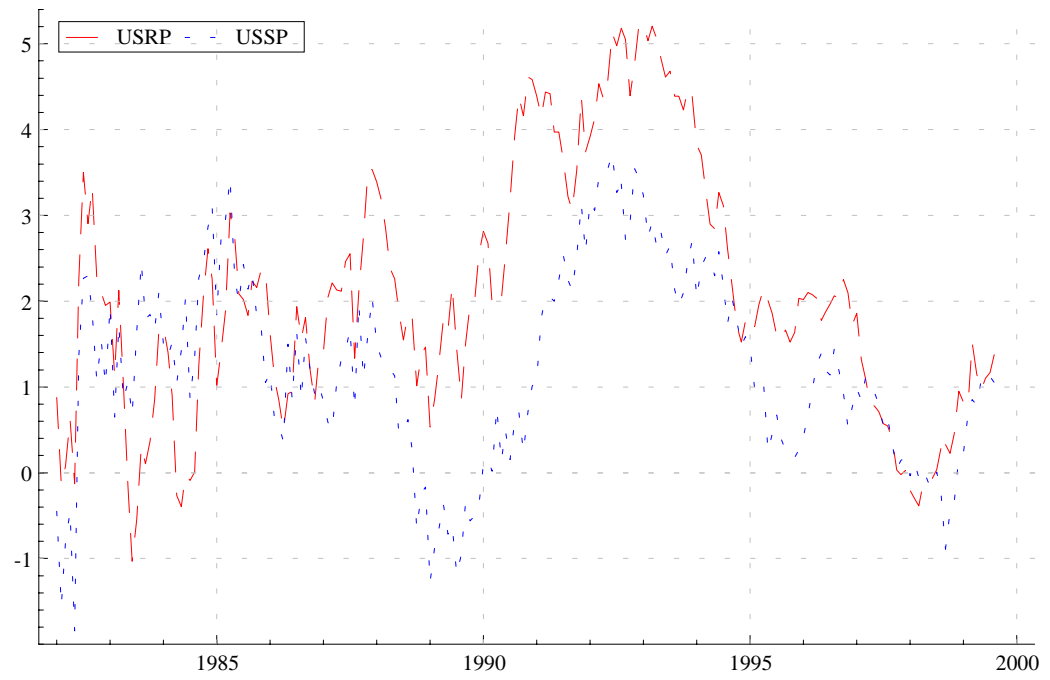

Figure 3: The spread between 10-Y bonds a 3-month yields (USSP) and the risk premium (USRP) in the US.

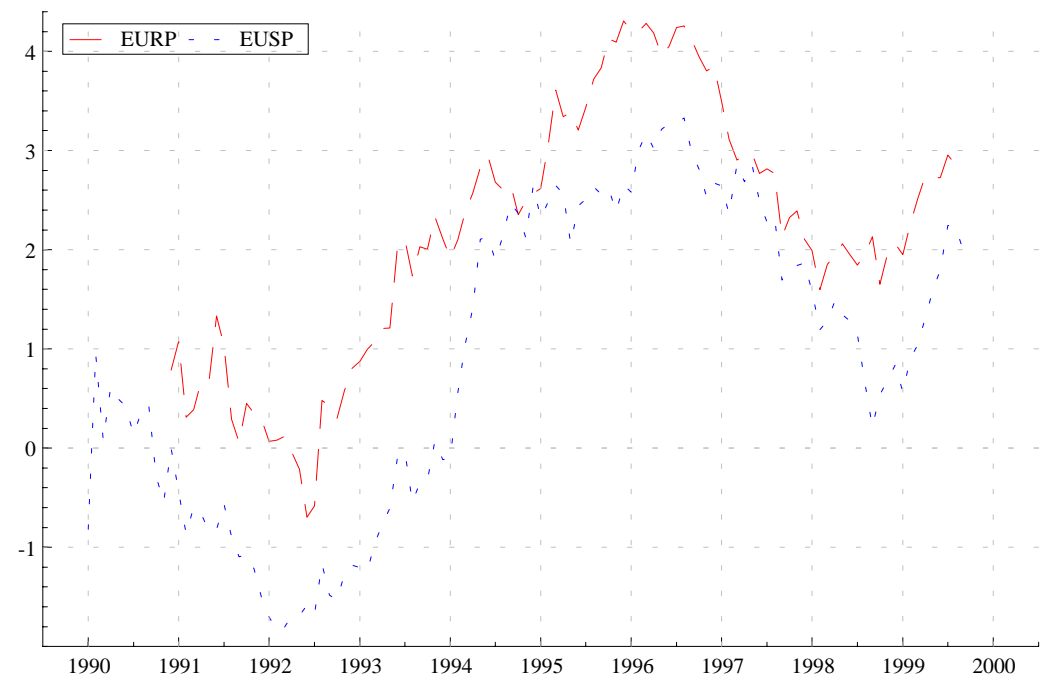

Figure 4: The spread between 10-Y bonds a 3-month yields (EUSP) and the risk premium (EURP) in Europe. 


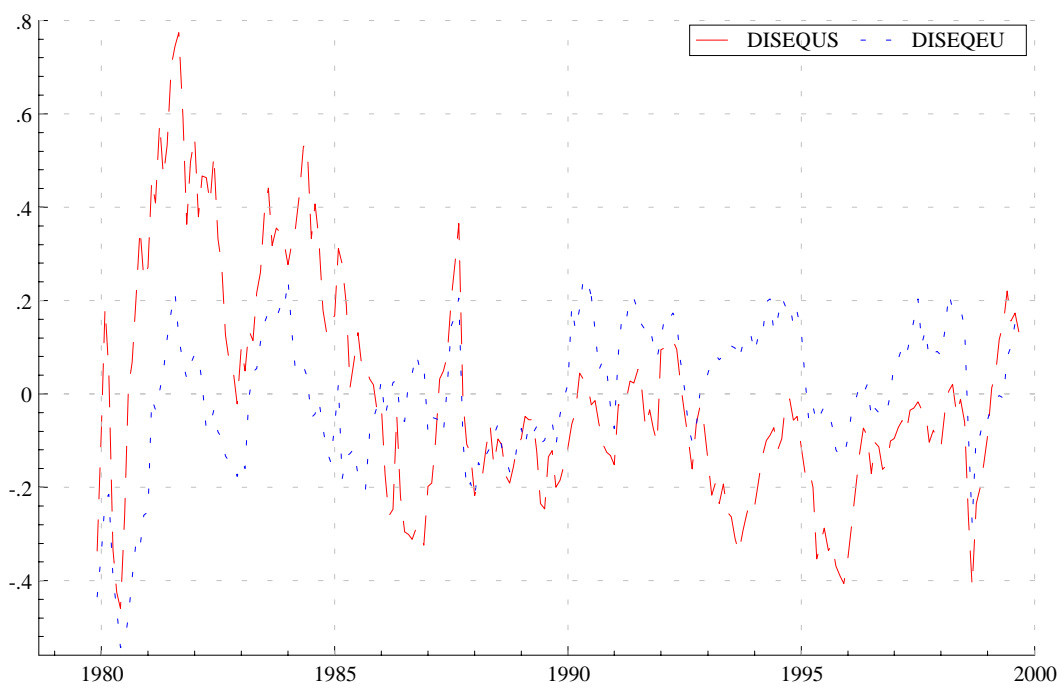

Figure 5: Disequilibria for US (DISEQUS) and European (DISEQEU) stock markets

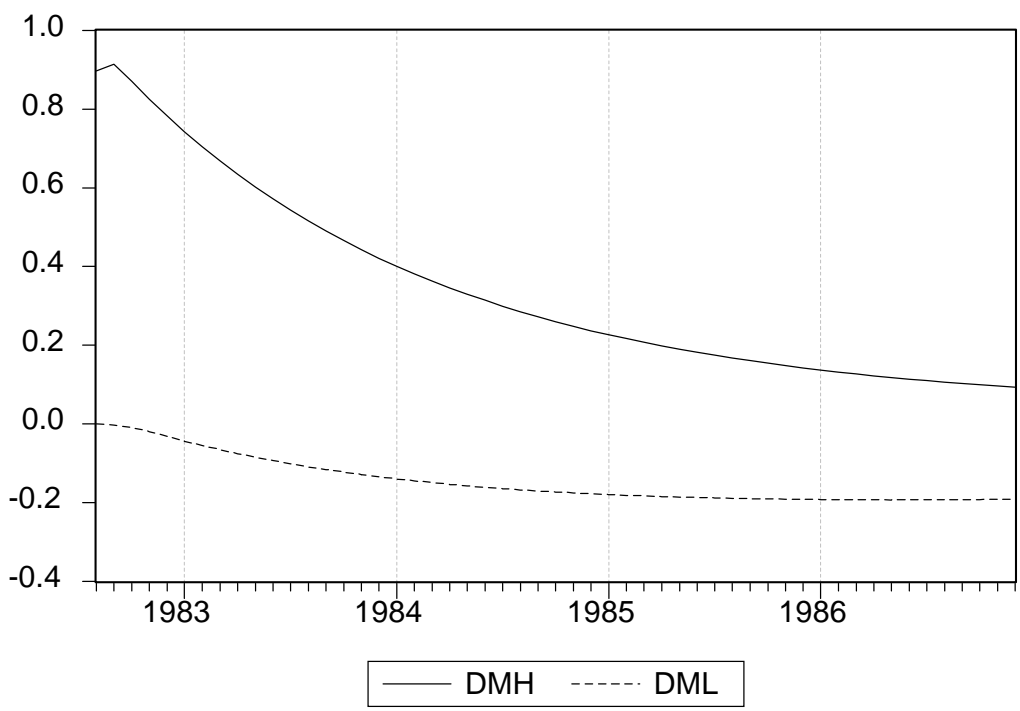

Figure 6: dynamic multipliers describing the response of European stock market to a sudden (DMH) and to a gradual(DML) correction in the US stock market 